\title{
Survival Time to Development of Hypertension and Its Predictors among a Cohort of Diabetic Patients in Health Facilities of Gurage Zone: A Retrospective Follow-Up Study
}

\author{
Biru Migora' \\ Mulugeta Geremew Geleso (iD) \\ Tadele Girum² \\ Meskele Bireda ${ }^{3}$ \\ Mehari Gebru ${ }^{2}$ \\ Samuel Dessu iD $^{2}$ \\ 'Department of Statistics, College of \\ Natural and Computational Science, \\ Wolkite University, Wolkite, Ethiopia; \\ ${ }^{2}$ Department of Public Health, College of \\ Medicine and Health Sciences, Wolkite \\ University, Wolkite, Ethiopia; \\ ${ }^{3}$ Department of Medicine, College of \\ Medicine and Health Science, Wolkite \\ University, Wolkite, Ethiopia
}

\begin{abstract}
Background: It is expected that around $50 \%$ of individuals with diabetes mellitus will develop hypertension in the course of medical follow-up. However, with strict medical follow-up and adherence to medical advice the incidence of hypertension can be highly reduced and the time to occurrence can be delayed. Therefore, this paper aimed to measure the time to development of hypertension and identify its predictors among a 10-year cohort of diabetic patients who have medical follow-up in health facilities of Gurage Zone.
\end{abstract}

Methods: An institution-based retrospective cohort study was conducted in diabetic followup clinics of Gurage Zone by reviewing 540 consecutively selected records among the records enrolled from January 1, 2010 to December 31, 2019. The outcome variable was incidence rate and survival time to the occurrences of hypertension (a systolic blood pressure at or above $140 \mathrm{mmHg}$ and/or a diastolic blood pressure at or above $90 \mathrm{~mm} \mathrm{Hg}$ and known hypertensive cases taken from adults' age $\geq 18$ years) among admitted diabetic patients (fasting blood sugar $\geq 126 \mathrm{mg} / \mathrm{dL}$ or random blood sugar $\geq 200 \mathrm{mg} / \mathrm{dL}$ ). Data were collected using a standardized checklist by trained professionals by reviewing records of all clients ever enrolled. Data were cleaned and entered by Epi info version 7 and analyzed by STATA. A Cox-proportional hazard regression model was built to identify predictors of development of hypertension.

Results: A total of 540 clients were followed for different periods with a median follow-up period of 2.3 years which gives 3,200 person-years of observation. Two hundred and seventy-six $(51.1 \%)$ participants were males and the mean age of was $52.2(+11.7)$ years. Three hundred $(55.6 \%)$ participants were urban dwellers. The overall incidence density rate (IDR) of hypertension in the cohort was 48.6 cases per 1,000 persons-year. Older ages adjusted hazard ratio $(\mathrm{AHR})=4.0(95 \% \mathrm{CI}=2.26-7.82)$, body mass index $(\mathrm{BMI})>25 \mathrm{~kg} / \mathrm{m}^{2}$ $\mathrm{AHR}=2.3 \quad(95 \% \quad \mathrm{CI}=1.06-3.68), \quad$ Type II diabetes mellitus (DM) AHR=2.0 (95\% $\mathrm{CI}=1.16-3.04)$, presence of comorbidity $\mathrm{AHR}=2.9(95 \% \mathrm{CI}=1.74-4.58)$, and poor drug adherence $\mathrm{AHR}=2.5(95 \% \mathrm{CI}=1.45-4.65)$ predicted the development of hypertension.

Conclusion: The risk of occurrences of hypertension among diabetic patients was high at the early periods and the risk was less at the late diabetic periods and the incidence density rate of hypertension among diabetic patients was high. In addition, age, BMI, type of DM, comorbidity, and drug adherence were independent predictors of occurrences of hypertension. Therefore, intervention to further reduce its occurrence has to focus on drug adherence and prevention of infection.

Keywords: hypertension, incidence, diabetes mellitus, survival
Correspondence: Biru Migora

Wolkite University, Wolkite, 07, Ethiopia

Email merratse@gmail.com 


\section{Background}

Hypertension and diabetes mellitus are the two most known global public health challenges and leading modifiable risk factors for cardiovascular disease (CVD) and death. ${ }^{1-3}$ Hypertension is defined as a systolic blood pressure at or above $140 \mathrm{mmHg}$ and/or a diastolic blood pressure at or above $90 \mathrm{~mm} \mathrm{Hg}$ and known hypertensive cases taken from adults' age $\geq 18$ years. ${ }^{4}$ Diabetes mellitus (DM) is a metabolic disorder characterized by abnormality of carbohydrate, fat, and protein metabolism and high blood glucose level which results from defects of insulin secretion, action, or both. ${ }^{5,6}$

Globally, the overall prevalence of hypertension in adults aged 25 and above was around $40 \%$ and estimated to cause 7.5 million deaths; about $12.8 \%$ of the total of all death. Its prevalence was estimated as $35 \%$ in high-income countries and $40 \%$ in low- and middle-income countries. ${ }^{7}$ Hypertension is even more prevalent (with 6-48\%) in SubSaharan Africa. ${ }^{8}$ In Ethiopia, several studies have reported that $10-30 \%$ of adults have hypertension. ${ }^{9-12}$

In Africa, DM affects 21.5 million (5.1\%) people and the total diabetes related death rate is 480,900 per year in the region. ${ }^{13,14}$ Studies have reported that the prevalence of diabetes in different settings ranges between 3 and $10 \%$. $^{12,13}$ Diabetes and high blood pressure tend to occur together because they share certain physiological traits or the same risk factors. ${ }^{1-3}$ Overall, the prevalence of hypertension among type 2 diabetic patients ranges between 50-70\%.,15-17

The coexistence of hypertension and type 2 diabetes increases the risk of the development and progression of macrovascular and microvascular complications in people with diabetes compared to the general population. ${ }^{1-3,15}$ Both hypertension and diabetes increase the risks of CVD, stroke, nephropathy, and retinopathy. ${ }^{2,15-17}$ Indeed, when hypertension coexists with diabetes, the risk of CVD is increased by 3-4-fold and it causes $86 \%$ of deaths in patients with DM. ${ }^{1,2,15-17}$

Anti-diabetic treatment initiation and adherence to medical care reduce the risk of hypertension by $20-40 \%$ and delay the complications by 4-6 years. ${ }^{1-3,15,17}$ Each 10 mmHg decrease in mean SBP reduces risk of any complication and death by $12 \%$ and $15 \%$, respectively. ${ }^{2,14-16}$ In developing countries like Ethiopia, since diabetic patients are diagnosed lateafter developing complications, estimating the incidence of hypertension among diabetic patients is very difficult and evidence is lacking. Therefore, this paper aimed to measure the time to development of hypertension and identify its predictors among a 10-year cohort of diabetic patients who have medical follow-up in health facilities of Gurage Zone.

\section{Methods \\ Study Design and Setting}

This health facility-based retrospective cohort study was conducted in health facilities found in Gurage Zone, Southern Ethiopia by reviewing a 10-year (2010-2019) cohort. Gurage zone is one of the 13 zones available in SNNPRs with a total population of about 1,609,908. Wolkite is the capital of the zone, located $158 \mathrm{~km}$ South of the capital city, Addis Ababa. The zone has 16 districts and five town administrations. ${ }^{18}$ There are 76 health centers and six hospitals (unpublished data). ${ }^{19}$ The study was conducted in the hospitals and district-based health facilities from January 1 to March 30, 2019.

\section{Study Population, Sample Size, and Sampling Technique}

The source population of this study was all adults (age 15 + ) diagnosed with DM and enrolled in the treatment/medical follow-up program in health facilities found in Gurage zone. Patients who were free from hypertension during the time of their first diagnosis were enrolled in the study. Of the 12 district level facilities and hospitals providing DM care, four facilities (Butajira General Hospital, Wolkite Health Center, Emdebir Health Center, and Gunchire Health Center) were randomly selected and the sample size was proportionally allocated to the facilities based on patient load. All the records of the diabetic patients enrolled from January 1, 2010 to December 31, 2019 at the selected health facilities in Guraghe Zone were included, and incomplete records were excluded from the study.

The sample size needed for the survival time and its comparison with a log rank test was calculated based on sample size estimation for the assessment of survival time under the Cox proportional hazards model by using the STATA Version 13.0 Statistical package computer program considering the following assumptions: a 1.84 hazard ratio (effect size) associated with the covariate BMI, ${ }^{22}$ the default 0.5 standard deviation of covariate of interest, with $5 \%$ marginal error and $15.5 \%$ probability of failure. The number of subjects needed to achieve a power of $80 \%$ and assuming $5 \%$ of subjects anticipated to withdraw from the follow-up was 574 . 


\section{Variables of the Study Dependent Variables}

Incidence density and survival time to development of hypertension which was measured in years from the date of treatment started to the date of outcome or event. If the client develops hypertension in the follow-up period it was considered as failure, censored otherwise.

\section{Independent Variables}

Age, sex, residence, initial weight, type of DM, duration of DM, family history of DM, family history of HTN, comorbidities at first date of diagnosis, comorbidities on the followup period, adherence status and type of treatment provided.

\section{Operational Definitions}

Diabetes Mellitus is defined by fasting blood sugar $\geq 126 \mathrm{mg} / \mathrm{dL}$ or random blood sugar $\geq 200 \mathrm{mg} / \mathrm{dL}^{6}{ }^{6}$

Hypertension is classed as systolic blood pressure at or above $140 \mathrm{mmHg}$ and/or diastolic blood pressure at or above $90 \mathrm{mmHg}$, and known hypertensive cases were taken from adults' age $\geq 18$ years. ${ }^{4}$

A body mass index between 18.5 and $25 \mathrm{~kg} / \mathrm{m}^{2}$ indicates a normal weight. A BMI of less than $18.5 \mathrm{~kg} / \mathrm{m}^{2}$ is considered underweight. A BMI between 25 and $29.9 \mathrm{~kg} /$ $\mathrm{m}^{2}$ is considered overweight. A BMI of $30 \mathrm{~kg} / \mathrm{m}^{2}$ or higher is considered obese. ${ }^{20}$

Adherence to anti-diabetic medications was defined as taking more than $80 \%$ of the prescribed treatment. ${ }^{21}$

\section{Data Collection Procedure and Data Quality Control}

The source of data for this study was documents of individual patients including registers and monitoring cards and patient admission book. Data was collected from client charts using a structured checklist for records review developed from the registers and follow-up charts. Four data collectors and two supervisors who are health professionals and working in DM clinics were recruited for data collection after getting training on the tool. The list of enrolled clients was obtained from DM follow-up charts. Individual patient cardex of those listed clients were obtained from card unit and necessary data were collected. A pretest was conducted in $5 \%$ of the total sample size at Wolkite Health center to check the consistency of the tool and to improve the skills of data collectors. In addition, the validity and reliability of the tool were checked.

\section{Data Processing and Analysis}

Data was cleaned, edited, coded, and entered into Epi-info version 7 and exported to STATA. After exploratory data analysis, bivariate analysis was performed to identify the association between variables. Hazard ratio, 95\% CI, and $P$-value were used to assess the strength of association and statistical significance. Incidence of hypertension with respect to person time at risk was calculated for groups. Variables significant at $P<0.25$ level in the bivariate analysis and variables which have medical/public health significance were included in the final Cox-regression analysis, to identify independent predictors of hypertension incidence. The forward stepwise regression method was applied to get a list of best predictors and any statistical test was considered significant at a P-evel less than 0.05 .

\section{Results}

\section{Sociodemographic and Clinical Characteristics of Study Subjects}

Out of 574 records, 34 were incomplete for major outcome. The remaining 540 records of DM patients who had normal blood pressure at the time of diagnosis were reviewed in this study. Two hundred and seventysix $(51.1 \%)$ participants were male and the mean age was $52.2(\mathrm{SD}=11.7)$ years. More than half $(54 \%)$ of the patients had normal BMI at the time of diagnosis. Regarding base line status, the median fasting plasma glucose level was $176 \quad(\mathrm{IQR}=145-253) \quad \mathrm{mg} / \mathrm{dL}$ (Table 1).

Among the study subjects, 400 (74.1\%) were type 2 diabetic patients. Four hundred and twenty-six (78.9\%) patients were with diabetes for a duration of less than 6 year with an average period of follow-up of 2.3 (IQR=1.3-5.4) years. Pertaining to the antidiabetic agents taken, $156(28.9 \%)$ used insulin alone, 50 (9.26\%) used insulin and oral antidiabetic agent together (Metformin and Glibenclamide, and the remaining334 (61.84\%) used oral antidiabetic agents (43.64\% Glibenclamide and 18.2\% Metformin) alone to manage their diabetes (Table 1).

\section{Survival Time from DM Diagnosis to Development of Hypertension}

The 540 patients were followed for different periods, with median of 2.3 years. During the follow-up time, $157(29 \%)$ patients developed hypertension. The incidence rate of HTN among the cohorts was assessed every 2 years interval. The overall incidence rate of 
Table I Socio-Demographic and Clinical Characteristics of the Study Participants

\begin{tabular}{|c|c|c|}
\hline Variables & Frequency & Percent \\
\hline \multicolumn{3}{|l|}{ Base line age in years } \\
\hline$<60$ years & 440 & 81.5 \\
\hline$>60$ years & 100 & 18.5 \\
\hline \multicolumn{3}{|l|}{ Sex of the patient } \\
\hline Male & 276 & 51.1 \\
\hline Female & 264 & 48.9 \\
\hline \multicolumn{3}{|l|}{ Place of residence } \\
\hline Urban & 300 & 55.6 \\
\hline Rural & 240 & 44.4 \\
\hline \multicolumn{3}{|l|}{ BMI } \\
\hline Normal & 292 & 54 \\
\hline Abnormal & 248 & 46 \\
\hline \multicolumn{3}{|l|}{ Family history of DM } \\
\hline Yes & 76 & 14.1 \\
\hline No & 462 & 85.6 \\
\hline \multicolumn{3}{|l|}{ Family history of HTN } \\
\hline Yes & 110 & 20.4 \\
\hline No & 430 & 79.6 \\
\hline \multicolumn{3}{|l|}{ Type of DM } \\
\hline Type I & 140 & 25.9 \\
\hline Type 2 & 400 & 74.1 \\
\hline \multicolumn{3}{|l|}{ Duration of DM } \\
\hline$<6$ years & 426 & 78.9 \\
\hline$>6$ years & 114 & 21.1 \\
\hline Base line FPG level & \multicolumn{2}{|l|}{$176 \mathrm{mg} / \mathrm{dL}(\mathrm{IQR}=145-253)$} \\
\hline \multicolumn{3}{|l|}{ Anti-DM taken } \\
\hline Insulin alone & 156 & 28.9 \\
\hline Insulin and oral agent & 50 & 9.3 \\
\hline Oral agent alone & 334 & 61.9 \\
\hline Follow-up time & \multicolumn{2}{|l|}{2.3 years $(1.3-5.4)$} \\
\hline \multicolumn{3}{|l|}{ Presence of comorbidity } \\
\hline Yes & 108 & 20 \\
\hline No & 432 & 80 \\
\hline \multicolumn{3}{|l|}{ Presence of new infection } \\
\hline Yes & 189 & 35 \\
\hline No & 351 & 65 \\
\hline \multicolumn{3}{|l|}{ Drug adherence } \\
\hline Good & 459 & 85 \\
\hline Poor & 81 & 15 \\
\hline
\end{tabular}

Abbreviations: BMI, body mass index; DM, diabetes mellitus; FPG, fasting plasma glucose; HTN, hypertension; IQR, interquartile range.

HTN among diabetic patients was 48.6 cases per comorbidities and new infections, and among type 2 1,000 persons-year of follow-up. The incidence of DM patients. The median hypertension free survival hypertension was high on aged patients, patient, with time was approximately 5.9 years. 


\section{Factors Influencing Development of Hypertension among Diabetic Patients}

The development of hypertension was considered a failure and the other outcomes considered as censored. Then, bivariate Cox proportional hazard regression analysis was conducted to select potential candidate variables to the multivariable analysis. In bivariate analysis, a significant difference was observed between predictors. Base line age in years, BMI, type of DM, duration of DM, presence of comorbidity, presence of new infection, and drug adherence were associated with the development of hypertension. Multiple Cox regression was fitted with forward stepwise method using the variables which have a $p$-value $<0.25$ in the bivariate analysis. After controlling the effect of other variables base line age in years, BMI, type of DM, presence of comorbidity and drug adherence predicted development of hypertension (Table 2).

After controlling the effect of confounders in multivariate analysis, the hazard of developing hypertension was 4-times higher in patients with baseline age $\geq 60$ years than their counterparts (AHR $=4.0, \quad 95 \%$ $\mathrm{CI}=2.26-7.82)$. Also, the hazard of developing hypertension was increased more than 2-fold for patients who have higher BMI than patients who have normal BMI (AHR $=2.3,95 \% \mathrm{CI}=1.06-3.68)$. Patients with type 2 DM were 2-times more likely to develop hypertension than type-1 DM patients ( $\mathrm{AHR}=2.0,95 \% \mathrm{CI}=1.16-3.04)$. Similarly, patients who had co-morbid conditions were 3-fold more at risk for development of hypertension than their counterparts $(\mathrm{AHR}=2.9, \quad 95 \% \quad \mathrm{CI}=1.74-4.58)$. Likewise, patients who poorly adhered to the medical treatment were 2.5-times more likely to develop hypertension than their counterparts (AHR $=2.5,95 \% \mathrm{CI}=.45-4.65)$ (Table 2).

\section{Discussion}

This study assessed the survival time from diagnosis to development of hypertension among diabetic patients who were free at base line in health facilities located in Gurage zone. It also assessed the predictors of hypertension development in the course of follow-up. Within this cohort, 540 patients were followed for 3,220 person years. During the follow-up, 157 patients developed hypertension, making the overall incidence rate of 48.6 cases per 1,000 personyear of follow-up. The incidence of death was significantly higher in older ages, high BMI, Type 2 DM, patients with comorbidity, and pooradherence patients.
In this study nearly one third of patients developed hypertension during the course of treatment. It is expected that around $50 \%$ of individuals with diabetes mellitus will develop hypertension in the course of medical follow-up. The pathologic conditions occurring during DM, like cholesterol accumulation and secondary vascular pathologies, lead to the development of hypertension. ${ }^{4,5,12,22-24}$ This was also evidenced through different studies conducted abroad. ${ }^{12,21}$

In the current study the survival time for the development of hypertension is 5.9 years. Although research is lacking in this area, general evidence indicated that a significant proportion of patients with diabetes mellitus will develop hypertension within a short period of time after diagnosis. It was also reported that a significant proportion of patients appear with hypertension even before the diagnosis of hypertension. Whether this will occur early or later depends on the level of BMI, type of DM, and other patient related factors. ${ }^{5,11,12,23}$

Consistent with the study conducted at Jimma University Medical Center, South West Ethiopia and Debre Tabor General Hospital, Northwest Ethiopia., ${ }^{25,26}$ we found that older age patients (age $>60$ ) were around 4-times more at risk of developing hypertension than patients who were less than 60 years of age. This is in line with the general theoretical aspect of hypertension, in which whenever age increases the risk of hypertension increases due to vascular pathologies and other factors. ${ }^{3,9-11}$ Similarly, the hazard of developing hypertension was increased by 2.3-times in patients with higher BMI compared to their counterparts. This study finding is consistent with a study conducted at Jimma University Medical Center, South West Ethiopia and Debre Tabor General Hospital, Northwest Ethiopia. ${ }^{25,26}$ It may be due to the fact that obesity is one of the major risk factors for the development of hypertension, even in normal weight patients. ${ }^{1,3}$ When obesity develops along with diabetes, the risk will be synergistic, as increased visceral and retroperitoneal fat may increase BP and, by activation of the sympathetic nervous system, activation of the renin-angiotensin system, and sodium retention, among other abnormalities. ${ }^{1,3,9-11}$

Likewise, the presence of comorbid conditions and poor adherence to the medications significantly increased the hazard of hypertension development. ${ }^{2,14,15}$ This is because cardiovascular comorbidities will reduce the elasticity of blood vessels and, in turn, lead to the development of hypertension..$^{5,11,12,14-16,19}$ Drug adherence has long been known to affect the outcome of treatment. As drug 
Table 2 Binary and Multiple Cox Regression Analysis of Factors Associated with HTN Development

\begin{tabular}{|c|c|c|c|c|c|}
\hline \multirow[t]{2}{*}{ Variables } & \multicolumn{2}{|c|}{ Hypertension } & \multirow[t]{2}{*}{ CHR $(95 \% \mathrm{Cl})$} & \multirow[t]{2}{*}{ AHR $(95 \% \mathrm{Cl})$} & \multirow[t]{2}{*}{$P$-value } \\
\hline & Yes & No & & & \\
\hline \multicolumn{6}{|l|}{ Base line age in years } \\
\hline$<60$ years & 116 & 324 & 1 & I & \\
\hline$>60$ years & 40 & 60 & $1.86(1.18-2.92)$ & $4.0(2.26-7.82)$ & 0.001 \\
\hline \multicolumn{6}{|l|}{ Sex of the patient } \\
\hline Male & 80 & 196 & $1.09(0.7-1.46)$ & - & \\
\hline Female & 76 & 188 & I & & \\
\hline \multicolumn{6}{|l|}{ Place of residence } \\
\hline Urban & 87 & 213 & I.0I (0.69-I.45) & - & \\
\hline Rural & 69 & 171 & I & & \\
\hline \multicolumn{6}{|l|}{ BMI } \\
\hline Normal & 72 & 220 & I & 1 & \\
\hline Abnormal & 84 & 164 & $1.56(1.07-2.8)$ & $2.3(1.06-3.68)$ & 0.001 \\
\hline \multicolumn{6}{|l|}{ Family history of DM } \\
\hline Yes & 22 & 54 & $1.03(0.58-1.73)$ & - & \\
\hline No & 134 & 330 & 1 & & \\
\hline \multicolumn{6}{|l|}{ Family history of HTN } \\
\hline Yes & 32 & 78 & $1.02(0.68-1.6)$ & - & \\
\hline No & 124 & 306 & I & & \\
\hline \multicolumn{6}{|l|}{ Type of DM } \\
\hline Type I & 30 & 110 & I & 1 & \\
\hline Type 2 & 126 & 274 & $1.66(1.05-2.63)$ & $2.0(1.16-3.04)$ & 0.001 \\
\hline \multicolumn{6}{|l|}{ Duration of DM } \\
\hline$<6$ years & 113 & 313 & I & & \\
\hline$>6$ years & 43 & 7I & $1.67(1.08-2.6)$ & - & \\
\hline \multicolumn{6}{|l|}{ Presence of comorbidity } \\
\hline Yes & 41 & 67 & $1.7(1.08-2.62)$ & $2.9(1.74-4.58)$ & 0.001 \\
\hline No & 115 & 317 & I & 1 & \\
\hline \multicolumn{6}{|l|}{ Presence of new infection } \\
\hline Yes & 65 & 124 & $1.5(1.02-2.2)$ & - & \\
\hline No & 91 & 260 & 1 & & \\
\hline \multicolumn{6}{|l|}{ Drug adherence } \\
\hline Good & 123 & 336 & I & I & \\
\hline Poor & 33 & 48 & $1.87(1.15-3.03)$ & $2.5(1.45-4.65)$ & 0.001 \\
\hline
\end{tabular}

Abbreviations: AHR, adjusted hazard ratio; BMI, body mass index; $\mathrm{Cl}$, confidence interval; CHR, crude hazard ratio; DM, diabetes mellitus; HTN, hypertension; IQR, interquartile range.

adherence helps to reduce the level of sugar in the blood, all the secondary effects could be minimized. ${ }^{4,14-16,19}$

\section{Strengths and Limitations of the Study}

This research discovered the incidence and time to development of hypertension among DM patients in clinical setups, which may be the first to do so in the country. Therefore, it may help to intervene in the existing problem. On the other hand, incompleteness of information and reliability of the recorded data such as the way blood pressure has been measured remains a major concern, since the data is obtained from record review. Also, facility related factors were not assessed in the study. 


\section{Conclusion}

In this study the overall incidence density rate (IDR) of hypertension development in the cohort was comparable with other studies. However, incidence was still higher, despite it being largely preventable The cumulative probability of survival and overall mean survival time were also comparable with other developing countries. The main predictors of incidence of hypertension were base line age in years, BMI, type of DM, presence of comorbidity, and drug adherence. Therefore, intervention to further reduce the incidence of hypertension has to focus on facilitating the screening program and early initiation and adherence of treatment. Also, due consideration is necessary to prevent developing complications, and prospective cohort studies will determine the factors which were missed through the records. Clinical experts should strengthen follow-up of diabetic patients, especially at the early periods.

\section{Abbreviations}

AHR, adjusted hazard ratio; BMI, body mass index; CI, confidence interval; CHR, crude hazard ratio; DM, diabetes mellitus; FPG, fasting plasma glucose; HTN, hypertension; IQR, inter quartile range.

\section{Data Sharing Statement}

The raw data set used for this study is offered by the corresponding author on reasonable request.

\section{Ethics Approval and Consent}

Ethical clearance was obtained from the institutional review office of Wolkite University. Permission to conduct the study also obtained from Gurage zone and district health departments. Permission was obtained from each clinic's officials. The study utilized existing admission information and patient histories, therefore no informed consent was required. All the patients' data obtained from records were de-identified in accordance with data protection regulations and the Declaration of Helsinki.

\section{Acknowledgments}

The authors would like to sincerely thank the head of the health departments, data collectors, and others who contributed to this work. We would also like to acknowledge Wolkite University for facilitating the study.

\section{Author Contributions}

All authors made a significant contribution to the work reported, whether that is in the conception, study design, execution, acquisition of data, analysis and interpretation, or in all these areas; took part in drafting, revising, or critically reviewing the article; gave final approval of the version to be published; have agreed on the journal to which the article has been submitted; and agree to be accountable for all aspects of the work.

\section{Funding}

There is no funding to report.

\section{Disclosure}

The authors declare no conflicts of interest.

\section{References}

1. Tesfaye S, Chaturvedi N, Eaton SEM, et al. Vascular risk factors and diabetic neuropathy. $N$ Engl J Med. 2005;352(4):341-350. doi:10.1056/NEJMoa032782

2. Sowers JR, Williams M, Epstein M, Bakris G. Hypertension in patients with diabetes. Strategies for drug therapy to reduce complications. Postgrad Med. 2000;107(4):47-60. doi:10.3810/ pgm.2000.04.990

3. Libby P, Nathan DM, Abraham K, et al. Report of the National Heart, Lung, and Blood Institute-National Institute of Diabetes and Digestive and Kidney Diseases Working Group on cardiovascular complications of type 1 diabetes mellitus. Circulation. 2005;111 (25):3489-3493. doi:10.1161/CIRCULATIONAHA.104.529651

4. Kiber M, Wube M, Temesgen H, et al. Prevalence of hypertension and its associated factors among adults in Debre Markos Town, Northwest Ethiopia: community based cross-sectional study. $B M C$ Res Notes. 2019;12(1):406. doi:10.1186/s13104-019-4431-9

5. Baynes HW. Classification, pathophysiology, diagnosis and management of Diabetes Melitis. $J$ Diabetes Metab. 2015;6:541. doi:10.4172/2155-6156.1000541

6. Shore HR, Shunu AB, Merid MM, Hawulte BA. Prevalence of hypertension and associated factors in Dire Dawa City, Eastern Ethiopia: a community based cross sectional study. Int J Hypertens. 2019;9878437. doi:10.1155/2019/9878437

7. Lloyd-Sherlock P, Beard J, Minicuci N, Ebrahim S, Chatterji S. Hypertension among older adults in lowand middle-income countries: prevalence, awareness and control. Int J Epidemiol. 2014;43 (1):116-128. doi:10.1093/ije/dyt215

8. Hendriks ME, Wit FW, Roos MTL, et al. Hypertension in Sub-Saharan Africa: cross-sectional surveys in four rural and urban communities. PLoS One. 2012;7(3):e32638. doi:10.1371/journal. pone. 0032638

9. Abebe SM, Berhane Y, Worku A, Getachew A. Prevalence and associated factors of hypertension: a crossectional community based study in Northwest Ethiopia. PLoS One. 2015;10(4):1-11. doi:10.1371/journal.pone.0125210

10. Helelo TP, Gelaw YA, Adane AA. Prevalence and associated factors of hypertension among adults in durame town, Southern Ethiopia. PLoS One. 2014;9(11):1-9. doi:10.1371/journal.pone.0112790

11. Gidav A, Tadesse B. Prevalence and determinants of hypertension in rural and urban areas of Southern Ethiopia. Ethiop Med J. 2011;49 (2):139-147 
12. Angaw K, Dadi AF, Alene KA. Prevalence of hypertension among federal ministry civil servants in Addis Ababa, Ethiopia: a call for a workplace-screening program. BMC Cardiovasc Disord. 2015;15:76. doi: 10.1186/s12872-015-0062-9

13. International Diabetes Federation (IDF). IDF Diabetes Atlas Sixth edition, 2017 Update. IdfOrg. 2017.

14. World Health Organization. Global Report on Diabetes. ISBN; 2016.

15. Unadike BC, Eregie A, Ohwovoriole AE. Prevalence of hypertension amongst persons with diabetes mellitus in Benin City, Nigeria. Niger $J$ Clin Pract. 2011;14(3):300-302. doi:10.4103/1119-3077.86772

16. Sachithananthan V. Prevalence of Diabetes Mellitus, Hypertension and Lipodystrophy in HAART Receiving HIV Patients in Southern Ethiopia. Int STD Res Rev. 2013;1(1):1-11. doi:10.9734/isrr/2013/1897

17. Muluneh AT, Haileamlak A, Tessema F, et al. Population based survey of chronic non-communicable diseases at gilgel gibe field research center, southwest ethiopia. Ethiop J Health Sci. 2012;22 (S):7-18.

18. Central Statistical Agency. Population and Housing Census of 2007. Ethiopia; 2007. Available from: https://www.statsethiopia.gov.et/wpcontent/uploads/2019/06/National_Statistical.pdf. Accessed May 14, 2021.

19. Gurage Zone health department. Annual Health Report for 2010 EFY. Gurage Zone health department; 2010.

20. Initiative NO. Obesity Education Initiative: clinical Guidelines on the Identification, Evaluation, and Treatment of Overweight and Obesity in Adults, National Institutes of Health, National Heart, Lung, and Blood Institute. Obes Res. 1998;6(Suppl 2):51S-209S.
21. Delamater AM. Improving patient adherence. Clin Diabetes. 2006;24 (2):71-77. doi:10.2337/diaclin.24.2.71

22. Janghorbani M, Aminorroaya A, Amini M. Hypertension in Non-Type 2 Diabetes in Isfahan, Iran: incidence and Risk Factors. Int J Hypertens. 2017;2017:1-7. doi:10.1155/2017/3132729

23. Zhou B, Lu Y, Hajifathalian K, et al. Worldwide trends in diabetes since 1980: a pooled analysis of 751 population-based studies with 4.4 million participants. Lancet. 2016. doi:10.1016/S0140-6736(16) 00618-8

24. Shaw JE, Sicree RA, Zimmet PZ. Global estimates of the prevalence of diabetes for 2010 and 2030. Diabetes Res Clin Pract. 2010;87 (1):4-14. doi:10.1016/j.diabres.2009.10.007

25. Abdissa D, Kene K. Prevalence and determinants of hypertension among Diabetic patients in Jimma University Medical Center, Southwest Ethiopia. Diabetes Metab Syndrome Obesity. 2020;13:2317-2325. doi:10.2147/DMSO.S255695

26. Akalu Y, Belsi Y. Hypertension and its associated factors among type 2 diabetes mellitus patients at Debre Tabor General Hospital, Northwest Ethiopia. Diabetes Metab Syndrome Obesity. 2020;13:1621-1631. doi:10.2147/DMSO.S254537
Vascular Health and Risk Management

\section{Publish your work in this journal}

Vascular Health and Risk Management is an international, peerreviewed journal of therapeutics and risk management, focusing on concise rapid reporting of clinical studies on the processes involved in the maintenance of vascular health; the monitoring, prevention and treatment of vascular disease and its sequelae; and the involvement

\section{Dovepress}

of metabolic disorders, particularly diabetes. This journal is indexed on PubMed Central and MedLine. The manuscript management system is completely online and includes a very quick and fair peerreview system, which is all easy to use. Visit http://www.dovepress. com/testimonials.php to read real quotes from published authors. 